Kong. Res. J. 4(2): 84-88, 2017

ISSN 2349-2694

Kongunadu Arts and Science College, Coimbatore.

\title{
INSIGHT INTO PHARMACEUTICAL IMPORTANCE OF BRYOPHYTES
}

\author{
Greeshma, G.M. ${ }^{1}$, G.S. Manoj ${ }^{2}$ and K. Murugan ${ }^{1 *}$ \\ 1Plant Biochemistry and Molecular Biology Lab, Dept. of Botany, University College, Thiruvananthapuram, \\ ${ }^{2}$ Dept. of Botany, VTM NSS College, Dhanuvachapuram, Thiruvananthapuram, Kerala, India. \\ *E.mail: harimurukan@gmail.com
}

\begin{abstract}
Historically, Bryophytes were accounted to be a monophyletic group and were placed in an inclusive Bryophyta. Some species are aquatic though some can adapt and live in arid regions. Bryophytes size ranges from microscopic to 12 inches in length, the average size is between $0.5-2$ inches long and colors vary from green to black and sometimes colorless. Bryophytes plays a vital role in the biosphere even their size is insignificant. As a biotic factor in the environment, they provide food for numerous herbivorous birds and animals. They prevent soil erosion by carpeting the soil. Bryophytes cause the outer portion of rock to slowly crumble as they grow with lichens on rock surfaces. And because of it they contribute and help to soil formation. When mixed with the soil, bryophytes increase the water-holding capacity of the soil and the amount of organic matter in the soil. Some bryophytes like sphagnum or peat moss has some economic importance. It is used as packing material for breakable or fragile objects such as figurines and dinnerware's. It is also used as packing materials for transporting plants and plant parts, since sphagnum holds water and hence prevent plants from drying during transport. As a whole, bryophytes are of little economic importance to man.
\end{abstract}

Keywords: Bryophytes, medicinal, non-vascular, microhabitat.

\section{INTRODUCTION}

Bryophytes are the ancient terrestrial chlorophyllous spore-forming amphibians, although no valid scientific documents for this have been appeared in the literature. This concept was fundamentally based on the similarity of the presentday liverworts the first land plant fossils, the spores of which date back almost 400 million years. They are taxonomically kept between the algae and the pteridophytes and there are appx. 14000 species of Bryophyta, 6000 of Marchantiophyta (liverworts),

300 of Anthoceratophyta, species and 5000 are mosses. Generally bryophytes are not infected or attacked by pathogens, insects, snails, slugs and mammals, however, studies on their phytochemistry have been neglected for centuries. Bryophytes are considered to be useless for human diets, difficulty of identification and collection of a large amount, although several liverworts have been used as medicinal plants in China to cure cut, burns, bruises, pulmonary tuberculosis, neurasthenia, fractures, convulsions, ulopathy, neurasthenia etc.

\section{REVIEW OF THERAPEUTICAL IMPORTANCE}

\subsection{Phytochemicals from bryophytes}

Bryophytes are known to produce diverse secondary metabolites to combat a number of biotic and abiotic stress such as predation, UV radiation, extreme temperature and microbial decomposition.
40 new carbon skeletal acetogenins, phenolic compounds and terpenoids have been found in this class, for example, marchantin A, marchantin $\mathrm{E}$ and riccardin $\mathrm{C}$ and diterpene dialdehyde, sacculatal, by recent development of spectroscopic apparatus, particularly by high resolution NMR techniques. The most interesting chemistry of liverworts is that most of sesqui- and diterpenoids are enantiomers of those found in higher plants and some different species of the same genus, like Frullania produce both normal and its enantiomeric sesquiterpenoid. They are the source of large variety of secondary metabolites and thus provide a great potential for biotechnological and biopharmaceutical applications. In past few years more than 400 novel chemical compounds were isolated from bryophytes and they were structurally elucidated. Some of biologically active compounds isolated from mosses includes biflavonoids, terpenes and terpenoids (like di- and triterpenoids) and flavonoids whereas liverworts reported to contain a large variety of lipophilic mono-, di- and sesquiterpenoids as well as aromatic compounds like bibenzyls, benzoates, cinnamates and naphtalenes. Flavonoids such as quercetin (182.5 $\mu \mathrm{g} / \mathrm{g})$, luteolin (464.5 $\mu \mathrm{g} / \mathrm{g})$, and apigenin $(297.5 \mu \mathrm{g} / \mathrm{g})$ were reported to be present in the liverwort Marchantia linearis (Remya et al., 2014). Two moss species Thuidium tamariscellum and Brachythecium buchananii were reported to be rich in secondary metabolites like flavonoids, terpenoids 
and phenols (Greeshma et al., 2016). In spite of the fact that many plant secondary metabolites are the potential therapeutic introduction of novel drugs in the market has decreased in past few years. In fact, higher plants and bryophytes have similar evolutionary history but search for novel therapeutic compounds within biodiversity of bryophyte remained neglected due to small size and lack of awareness among people. These small plants remained unexploited so far in drug discovery process in spite of few reports from the past depicts some of their ethnomedicinal uses. Studies on secondary metabolites of bryophytes have revealed the presence of few original compounds, some of which are not synthesized by higher plants (Rashmi et al., 2014).

\subsection{Antimicrobial aspects of Bryophytes}

Bryophytes have been reported as antibiotics (Tedela et al., 2014). Various organic solvent extracts of bryophytes have been investigated in past. Literature emphasizes that the alcoholic and the aqueous extracts or the various compound isolated from different species of bryophytes (hepatic and mosses) have shown antimicrobial effects against various group of fungi, as well as Gram negative and Gram positive bacteria. Recently extracts of few of the selected species of bryophytes (seven mosses and three liverworts) viz the Radula flacida, Cyatodium africanum, Frullania spongiosa, Thuidium gratum, Ectropothecium aeruginosum, Sematophyllum caespitosum, Stereophyllum radiculosum, Babulalam berenensis, Campilopusa spericuspis and Calympereserosumlam berenensis, Campilopusa spericuspis and Calymperes erosum have shown interesting antimicrobial activity (Rashmi et al., 2014). Similarly, the methanolic and water fractions of Targionia hypophylla possess strong microbicidal activity (Remya et al., 2012). The methanolic and aqueous extracts of Plagiochilla beddomei, Leucobryum bowringii and Octoblepharum albidum exhibited different degree of growth inhibition against bacterial species such as Salmonella typhimurium, Staphylococcus aureus, Klebsiella pneumonia, E.coli, Bacillus cereus and Pseudomonas aeruginosa and fungal species like Candida albicans, Cryptococcus neoformans, Trichophyton rubrum, Mucor indicus, Apergillus niger and A. flavus (Manoj, 2012). Therefore, the potential antimicrobial properties of bryophyte can be harnessed for the therapeutic purpose against the respective pathogen. The antibacterial and antifungal activities of bryophytes have been discussed in below.

\subsection{Microbicidal potential}

In recent year extensive studies have been conducted for the search of antibacterial properties in different species of plant. Organic extracts of various medicinal plants containing flavonoids have been reported to show antimicrobial activity (Praveen Dahiya et al., 2012). The antibacterial activities of isofavonoids and flavonoids, and glycosides of luteolin and apigenin have also been reported. But most of the investigations were centered on angiosperms. Few data are presently available about these smaller groups of plants, bryophytes. However, few of the recent study on bryophytes has shown some of the antibacterial activity against gram-positive and gram-negative bacteria (Meenakshi et al., 2011).

Also, various phenolic compounds isolated from Atrichum, Dicranum, Mnium, Polytrichum, and Sphagnum spp. are known to shown antimicrobial properties. Apart from this the antimicrobial activity for three moss species Eurhynchium angustirete, Rhytidia delphussquarrosus and Rhodo bryumroseum, and for two liverwort species Frullania dilatata and Lophocolea heterophylla has been reported for the first time. Similarly, aqueous extract of few bryophytes have some inhibitory effect on the growth of Escherichia coli as tested on plates. However, this antibacterial activity seems to be specific for certain bryophyte species, as the extracts of Marchantia polymorpha, Porella platyphylla and the moss Dicranum scoparium showed antimicrobial effects on the gram-positive bacteria namely Bacillus subtilis, Staphylococcus aureus and Sarcina lutea, but no activity against gram-negative E. coli (Rashmi et al., 2014).

Many of the bryophyte species are also known to show antifungal property (Abhijit et al., 2011). Different crops growing in greenhouses, like tomatoes, wheat and green pepper were infected with the pathogens Phytophora infestans, Erysiphe graminis and Botrytis cinerea and later treated with alcoholic extracts from different bryophytes. All bryophyte extracts showed a species-specific antifungal activity against the plant pathogenic fungi depending on the concentration. Ethanolic extract of Marchantia linearis exerted a potent fungicidal activity against Botrytis cinerea and marginally in Rhizoctonia solani i.e., showing varied levels of growth inhibition with different concentrations. (Remya et al., 2014). Furthermore, extracts from Neckera crispa and Porella obtusata showed antifeeding effects against the Portuguese slug Aarion lusitanicus. In view of the above features that bryophyte extracts showed fungicidal and 
antifeedant effects, a commercial product was developed and is sold as natural pesticide. Apart from this studies conducted in the past have revealed few of the compounds isolated from bryophytes extracts have shown reversal of conventional antibiotic resistance development in pathogenic fungi. Therefore, the problem of drug resistance development in pathogenic fungi can be solved easily (Rashmi et al., 2014).

Also, in addition to this studies conducted on one of the model species of moss Physcomitrella patens revealed that this moss under axenic condition produces a tetracyclic diterpene, namely 16 $\alpha$-hydroxykaurane (16 $\alpha$-hydroxy-ent-kaurane, Kaurenol, $\mathrm{C}_{20} \mathrm{H}_{34} \mathrm{O}$ ) (Anna et al., 2010). Although, the utility of $16 \alpha$-hydroxykaurane is not yet revealed, but it is presumed to be bioactive. This, compound is known to be produced by lichen species and fungi and it is commonly known from Gibberella fujikuroi, a plant pathogenic fungus that infects rice plants and causes foolish rice seedling disease. As recently shown, 16 $\alpha$-hydroxykaurane is involved in spore germination in Physcomitrella patens and leads to a complete inhibition of spore germination when applied in high concentrations $(2-3 \mu \mathrm{M}$ ) (Anna et al., 2010). Also, few bryophyte extracts have been found to be effective on human pathogenic fungi although the bioactive compounds may cause allergenic effects and dermatitis in few cases. Nevertheless due to risk of allergic reactions, bryophyte extracts were not recommended for scientific medicinal use so far.

\subsection{Phytochemicals vs pharmacologicalpotential}

Since bryophytes are the reservoir of complex secondary metabolites, their vast application in traditional medicine is not astonishing. A large number of bryophytes are used as medicines in homeopathy. About $3.2 \%$ of mosses and $8.8 \%$ of liverworts taxa have been chemically investigated. Species like Sphagnum, Marchantia, Riccia, Barbula, Bryum, Octeblepharum and Fontinalis are used to treat different diseases, including cardiovascular diseases, inflammation, fever, lung diseases, infections, wounds and skin diseases (Rashmi et al., 2014). In China more than 30 species can be bought at the local pharmacist 66 and around 40 different kinds of bryophytes have been used to treat diseases of cardiovascular system, tonsillitis, tympanitis cystitis and bronchitis and to cure skin disease and burns. Many of the species for example Polytrichum commune which is used as antipyretic and antiinflammatory agent or boiled as a tea for treating the cold. Rhodobryum giganteum is another species traditionally used to treat, other diseases like cardiovascular diseases or angina (Rashmi et al.,
2014). According to the some of the recent report bryophytes are the source of numerous chemical compounds of biotechnological and biopharmaceutical interest. Several secondary metabolites have been isolated so far from different species but the mechanisms behind their activity are still widely unexplored.

\subsection{Antioxidant potential}

Few of the bryophyte species have been studied in context to antioxidant activity. Recent study suggests that some of the liverworts and moss possesses strong antioxidative machinery which helps them to survive in the extreme climate and stress condition. Heavy metal, desiccation and ultraviolet radiation have been found to trigger an array of different enzymes in bryophytes (Rashmi et al., 2014). Few of the bryophyte species have been found to hyper accumulate metals and few others were able to sequester the toxic metals. The study conducted on antioxidant activity of the Antarctic mosses Sanionia uncinata and Polytrichastrum alpinum var. alpinum has indicated their potential to be used as antioxidants for medicinal and cosmetic purpose. The methanolic extracts of Plagiochilla beddomei, Leucobryum bowringii and Octoblepharum albidum possess potential antioxidant properties (Manoj, 2012). Also, in addition the antioxidant activities of some of the species of bryophyte like Atrichum undulatum. Polytrichum formosum, Pleurozium schreberi and Thudium tamariscinium has been screened, and all tested species have showed antioxidant effects lower than the positive control, caffeic acid (Boris et al., 2012). Moreover, the screening for the antioxidant property of the aqueous extract of the three moss namely Brachythecium rutabulum, Calliergonella cuspidate and Hypnum mammillatum in context of their ABTS (2, 2- azino- bis ( 3 - ethlybenzthiozoline- 6 sulphonic acid) cation scavenging activities and phenolic content have known to show some positive response. Out of the three extracts, Brachythecium rutabulum have shown the highest of the phenolic content which further suggested potential of this extract in search of many other novel antioxidant compounds in this moss. Apart from this methanolic and and ethyl acetate extract of Marchantia polymorpha have also shown antioxidant property. Summing up, bryophyte could be the source of many novel antioxidants if screened which could be used for novel drug discovery.

\subsection{Biopharming for phytochemicals}

Bryophytes have indeed penetrated the fore front of modern medicines. Although a vast variety of biopharmaceuticals has been produced in microbial 
or mammalian cells but plants based production system possesses several advantages over the mammalian and microbial system thus, making them interesting alternatives. Microbial systems are favored because of easy cultivation and high productivity, whereas mammalian cell lines (preferentially Chinese Hamster Ovary cells) are favored for complex multimeric proteins or those requiring posttranslational modifications (Rashmi et al., 2014). In contrast to these currently used systems, plants based production system possesses several advantages over these system thus making them interesting alternatives. As higher eukaryotes, they perform posttranslational modifications closely resembling those of humans, thus minimizing the risk of product contamination by infectious agents derive from the used cells or media (Rashmi et al., 2014). Also bryophytes offer the researchers and the company a high production system which can be grown without antibiotics, hence avoiding the danger of contamination of the final product. Apart from these advantages, mosses are the only plants known to show a high frequency of homologous recombination. They allow stable integration of inserted genes into the host cell. Furthermore, the highly complex moss system, compared to bacteria and fungi, permits a much wider array of expression than is possible in other systems. In view of the above advantages of mosses over other production system, today, many complex biopharmaceuticals are being produced by moss bioreactors. The Chair of plant Biotechnology from the University of Freiburg, Germany, and the biopharmaceutical company Greenovation Biotech Gmbh in Heilbronn, Germany; have started a cooperation to enhance the yield of recombinant proteins from moss. The moss Physcomitrella patens has been successfully grown in a bioreactor which require only water and minerals to nourish the moss, in the presence of light and $\mathrm{CO}_{2}$ (Greenovation). Consequently many complex proteins can be produced in moss bioreactor. Other products are human growth factor that is required by the researcher for tissue culture. This plant has successfully been able to produce human proteins and is the only plant being used to produce the blood-clotting factor IX for pharmaceutical use.

\section{CONCLUSION}

Use of medicinal plants has been appreciated due to low cost and lesser side effects. Herbal drugs have been used successfully in the treatment of various ailments over the last few decades. Development of drug resistance in pathogens is one of the major problems in medicine. Natural products derived from the botanicals can be used as a substitute to solve the problem. A number of herbal compounds have been discovered with immense therapeutic potential. Therefore, to meet the potential future demand for various bioactive compounds used as drugs, a new production system is required significantly. Bryophyte, a small and apparently insignificant group of plants may serve as a source of some unique biologically active molecules. Many of the bryophytes are important source of medicine, antibacterial and antifungal agents. Antifungal efficacy of certain liverworts and mosses can substitute the conventional synthetic fungicides used in crop protection especially in the countries where fugal invasion in the crop fields is a common phenomenon. The problem of development of drug resistance in common human pathogenic fungi can be solved by using antifungal compounds harvested from uncommon sources like bryophytes. Several bryophytes are able to produce antifungal compounds. Furthermore, the use of moos bioreactor has opened new possibilities for the production of many plant and animal metabolites.

Future scope: In the past few years, rapid progress has been made to isolate various plant based therapeutic compounds. Bryophytes being rich source of a variety of secondary metabolites could be a promising source of the bioactive compounds with immense therapeutic potential. Being present in varied niche and occupying the most diverse group of plant kingdom, they could be the source of various evolved metabolic pathways that could be wisely manipulated for the development of various novel therapeutic compounds. Therefore, bioprospecting of bryophytes is required to discover the natural wealth of bryophytes. Creation and development of production system by using bryophyte cells could solve the future demand of novel plant based production system. Hence, engineering of metabolic pathway for production of novel metabolites, and strategies for the development of the bioprocess for bryophyte cell system is the need of time to dig out some more information to satisfy the thirst of novel drug discovery.

\section{REFERENCES}

Abhijit, Dey and Jithendra Nath De, (2011). Antifungal bryophytes. Possible role against human pathogens and in plant protection. Res. J. Bot. 6(4):129-140.

Anna, K.B., L.D. Eva, F.Wolfgang, L.Daniel, V.S. Marco, D.Z. Andreas and Ralf Reski, (2010). Applied Bryology - Bryotechnology. Trop. Bryol. 31: 2232. 
Boris, Pejin. and Jelena Bogdanović-Pristov, (2012). ABTS Cation scavenging activity and total phenolic content of three moss species. Hem. Ind. 66(5): 723-726.

Greeshma, G.M. and K. Murugan, (2016). Prelimary phytochemical screening of Brachythecium buchananii (Hook) A.Jaeger and its medicinal value. JPSI 5(2): 66-68.

Greeshma, G.M. and K. Murugan, (2016). Proximate composition and phytochemical analysis of solvent extract of Thuidium tamariscellum (c.muell.)Bosch. and sande-lac. A moss. WJPR. 5(3): 747-754.

Manoj, G.S., (2012). Screening of secondary metabolites from Plagiochilla beddomei Steph., Leucobryum bowringii Mitt. and Octoblepharum albidum Hedw. (Bryophytes) and their antioxidant and antimicrobial potentiality (Ph.D. thesis). Department of Botany. University College, Thiruvananthapuram, Kerala, India.

Meenakshi, Singh., Shweta Singh, Virendra Nath, Vinay Sahu and Ajay Kumar Singh Rawat, (2011). Antibacterial activity of some bryophytes used traditionally for the treatment of burn infections. Pharm. Biol. 49(5): 526-530.

Praveen, Dahiya and Sharmishtha Purkayastha, (2012). Phytochemical Screening and
Antimicrobial Activity of Some Medicinal Plants Against Multi-drug Resistant Bacteria from Clinical Isolates. Ind. J. Pharm. Sci. 74(5): 443450.

Rashmi, Mishra., Vijay Kant Pandey and Ramesh Chandra, (2014). Potential of bryophytes as therapeutics. IJPSR. 5(9): 3584-3593.

Remya, Krishnan., K.V. Kannan and K. Murugan, (2014). Antifungal activity of the ethanolic extracts of Marchantia linearis Lehm and Lindenb. against some pathogenic fungi. Int. J. Aquat. Biol. 2: 556 to 563.

Remya, Krishnan., V.S. Anilkumar and K. Murugan, (2014). Establishment of cell suspension culture in Marchantia linearis Lehm andLindemb. for the optimum production of flavonoids. Biotech. 4(1): 49-56.

Remya, Krishnan., G.S. Manoj and K. Murugan,(2012). Invitro microbicidal potentiality of Targionia hypophylla L. And Bryum species- bryophytes. Int. J. Pharm. Pharm. Sci. 4(2):410-413.

Tedela, P.O., A.O. Adebiyi and A. Aremu, (2014). In Vitro Antibacterial Activity of Two Mosses: Calymperes Erosum C. Mull and Bryum coronatum Schwaegr from South-Western Nigeria. JBL 5(2):77-84. 